\title{
Contemplative Practices and Mental Training: Prospects for American Education
}

\author{
Mind and Life Education Research Network (MLERN): Richard J. Davidson, ${ }^{1}$ \\ John Dunne, ${ }^{2}$ Jacquelynne S. Eccles, 3 Adam Engle, 4 Mark Greenberg, 5 \\ Patricia Jennings, ${ }^{5}$ Amishi Jha, ${ }^{6}$ Thupten Jinpa, ${ }^{7}$ Linda Lantieri, ${ }^{8}$ David Meyer, ${ }^{3}$ \\ Robert W. Roeser, 9 and David Vago ${ }^{10}$ \\ ${ }^{1}$ University of Wisconsin, ${ }^{2}$ Emory University, ${ }^{3}$ University of Michigan, ${ }^{4}$ Mind and Life Institute, \\ ${ }^{5}$ Pennsylvania State University, ${ }^{6}$ University of Miami, ${ }^{7}$ Institute of Tibetan Classics, ${ }^{8}$ Inner Resilience \\ Program, ${ }^{9}$ Portland State University, and ${ }^{10}$ Harvard Medical School
}

ABSTRACT-This article draws on research in neuroscience, cognitive science, developmental psychology, and education, as well as scholarship from contemplative traditions concerning the cultivation of positive development, to highlight a set of mental skills and socioemotional dispositions that are central to the aims of education in the 21 st century. These include self-regulatory skills associated with emotion and attention, self-representations, and prosocial dispositions such as empathy and compassion. It should be possible to strengthen these positive qualities and dispositions through systematic contemplative practices, which induce plastic changes in brain function and structure, supporting prosocial behavior and academic success in young people. These putative beneficial consequences call for focused programmatic research to better characterize which forms and frequencies of practice are most effective for which types of children and adolescents. Results from such research may help refine training programs to maximize their effectiveness at different ages and to document the

The activities of the Mind and Life Education Research Network and the writing of this manuscript were supported by a grant from the John W. Kluge Foundation and from the Mind \& Life Institute.

Correspondence concerning this article should be addressed to Richard J. Davidson, University of Wisconsin, Madison, 1500 Highland Avenue, Madison, WI 53705; e-mail: rjdavids@wisc.edu.

(C) 2012 The Authors

Child Development Perspectives $(\odot 2012$ The Society for Research in Child Development DOI: $10.1111 / j \cdot 1750-8606.2012 .00240 . x$ changes in neural function and structure that might be induced.

KEYWORDS-contemplative practice; neuroscience; education; attention; emotion regulation

Current global conditions, including increasing economic interdependence, widespread intercultural contact, and the emergence of knowledge-based societies, require new forms of education (Partnership for 21st Century Skills, 2011). As central cultural contexts of human development, schools play a major role in cultivating the kinds of mental skills and socioemotional dispositions that young people will need to realize productive, satisfying, and meaningful lives in the 21 st century (Heckman, 2007).

Drawing on research in neuroscience, cognitive science, developmental science, and education, as well as on insights from contemplative traditions concerning the cultivation of virtuous qualities, we highlight a set of mental skills and socioemotional dispositions that we believe are central to the aims of education in the 21 st century. These include self-regulatory skills associated with emotion and attention, self-representations, and prosocial dispositions such as empathy and compassion.

Research is beginning to document how positive mental skills and socioemotional dispositions support academic success and prosocial behavior in young people (Zins, Weissberg, Wang, \& Walberg, 2004). Consistent with contemplative insights into mental training, research indicates that qualities such as emotion regulation can be cultivated and can change the mind and brain (Urry et al., 2006), much like other skills are learned through sustained repetitive practice that over time leads to automatized habit (Fischer \& Bidell, 1998). 


\section{AN ORGANIZING FRAMEWORK}

Figure 1 depicts a framework for understanding how contemplative practices may affect neural systems, psychological functions, and behavioral outcomes. By contemplative practices, we refer to a wide variety of strategies and methods originally rooted in contemplative traditions such as Buddhism. In modern scientific terms, these practices are forms of mental and behavioral training that are intended to produce alterations in basic cognitive and emotional processes, such as attention and the regulation of certain forms of negative affect, and to enhance particular character traits that are considered virtuous, such as honesty and kindness. As Figure 1 illustrates, many people within the educational context may benefit from contemplative practice, including administrators, principals, counselors, teachers, and students. (Of course, parents are also important, although they fall outside the educational context per se.) There is much to say about each of these groups, but this article will focus on applying contemplative practices to students. The figure depicts three levels that may reflect the potential impact of contemplative practices: neural substrates, psychological functions, and behavioral outcomes. Extant evidence suggests that contemplative practices can effect change in measures that reflect each of these different levels. Such practices likely operate directly on psychological functions such as attention and emotion regulation, which are subserved by alterations in neuronal processes that are visible to modern neuroimaging methods. Some evidence also suggests that contemplative practice occurring over more extended periods can induce both structural and

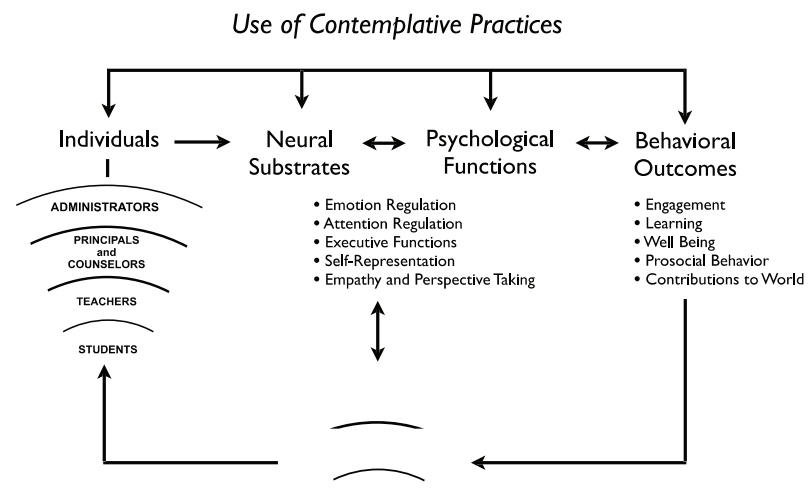

Cultivation of Healthy Educational Contexts

Figure 1. Model of the psychological constructs most impacted by contemplative practices and the key behavioral outcomes that are being studied. Note. The classes of individuals who might benefit from such mental training are delineated on left and include all of the major constituents in a school system. Contemplative practices impact specific neural substrates and in turn impact key psychological constructs leading to specific behavioral outcomes. Other school-related more macro variables such as the leadership, school culture, and classroom environment are also noted as these will impact the key neural and psychological systems as well. functional changes in the brain. Finally, changes in neural substrates and psychological functions will lead to alterations in measurable behavioral outcomes.

Few studies have included measures in the same individual at each of these different levels over the course of contemplative training. It is only when we piece together the available strands of evidence from many different studies that a more coherent picture of the transformations across different levels of analysis emerges. In the sections below, we first consider research on the impact of contemplative practices, and we then place these findings within a developmental context. The concluding section offers some suggestions and recommendations for future research.

\section{RESEARCH ON CONTEMPLATIVE PRACTICES}

Contemplative practices such as meditation and yoga are structured and socially scaffolded activities that train skills by placing some constraint or imposing some discipline on a normally unregulated mental or physical habit. A defining characteristic of such practices is that they require individuals to exercise volitional control to sustain the focus of attention on particular objects (such as the breath) or mental contents (such as the suffering and relief from suffering of particular individuals). Other objects of attentional focus may include moment-to-moment fluctuations in the "stream of consciousness" in order to develop the ability to concentrate, to effectively understand and manage stress and emotion, to gain knowledge about oneself, and to cultivate prosocial dispositions. With such sustained practice, complex skills like mindfulness and empathy likely become routinized at neural and mental levels and, subsequently, regulate behavior more or less automatically by being highly accessible and available (Higgins, 1996).

Various contemplative practices such as meditation are increasingly integral components of interventions that have been found to promote general wellness and alleviate a variety of medical symptoms. Perhaps the most widely implemented model of a meditation-based approach is mindfulness-based stress reduction (MBSR), an 8-week program designed for both normal and clinical populations that incorporates both mindfulness and compassion-based elements (Kabat-Zinn, Lipworth, \& Burney, 1985). MBSR provides systematic training in meditation as a self-regulatory approach to stress reduction and emotion management. Studies have shown its efficacy for improving chronic pain, rheumatoid arthritis, fibromyalgia, anxiety, and depression (Arias, Steinberg, Banga, \& Trestman, 2006), as well as different indices of immune and endocrine function (Witek-Janusek et al., 2008).

One reason for these alterations in health may be that MBSR strengthens neural systems important for emotion regulation. These findings suggest that training and practice specifically designed to cultivate positive qualities such as emotion regulation and mindfulness may also produce beneficial 
alterations in brain function and structure. Presumably, these alterations would be most prominent in long-term, advanced practitioners, but evidence indicates that even very brief cognitive reappraisal training $(30 \mathrm{~min})$ in emotion regulation can produce reliable alterations in brain function (Urry et al., 2006).

There is also growing evidence that mindfulness training improves adults' ability to regulate attention and executive function, including orienting attention and monitoring conflict (Jha, Krompinger, \& Baime, 2007) and inhibiting emotionally charged but irrelevant information (Ortner, Kilner, \& Zelazo, 2007) in novice meditators. Intensive meditation practice improves performance on the attentional blink task and decreases reaction time variability in a selective attention task, altering functional brain activity that supports these attentional changes (Lutz et al., 2009; Slagter et al., 2007). In adults, meditation practice can also induce present-oriented forms of self-awareness (Farb et al., 2007) that likely enhance motivation and learning (Roeser \& Peck, 2009). Training likewise enhances the neural circuits that underlie empathy in adults (Singer \& Lamm, 2009). Finally, studies of people with at least $10,000 \mathrm{hr}$ of formal meditation practice underscore the potential for enduring cognitive, emotional, and neuroplastic change (Lutz, Slagter, Dunne, \& Davidson, 2008), and provide a scientific warrant for educational interventions that aim, through sustained regular practice, to cultivate attention, emotion regulation, and empathy (Diamond \& Lee, 2011).

\section{BASIC RESEARCH ON HUMAN DEVELOPMENT}

Important developmental changes in brain structure and function guide emotional and cognitive development. Gray-matter volume peaks in late childhood (ages 9-11 years) and then declines, whereas white-matter volume, which supports connections among brain regions, continues to increase into early adulthood and possibly beyond. The functional consequences include more efficient communication between the prefrontal cortex (PFC) and other cortical and subcortical regions, enabling better regulation of thought, emotion, and action (Paus, Keshavan, \& Giedd, 2008). During adolescence, the PFC and subcortical structures associated with memory (such as the hippocampus) are particularly plastic and highly vulnerable to poorly managed stress or prolonged allostatic load (Andersen \& Teicher, 2008). These cortical and subcortical areas are also very likely to be highly sensitive to positive influences during development, although little research has directly addressed this issue. In this article, we review basic research on the core mental and behavioral processes that are potential targets of contemplative interventions. In doing so, we intend to set the stage for synergistic collaboration between scientific research on contemplative practice and educational programs designed to foster the cognitive, emotional, social, and ethical development of 21 st-century youth.

\section{Emotion and Emotion Regulation}

Clearly, the brain can change in response to experience and training, and environmental influences shape brain function and structure. A large corpus of research in animals indicates that stressful events harm the brain. In adult male rodents, environmental stressors such as restraint, tail shock, and sleep deprivation cause dramatic levels of immunosuppression, cardiovascular dysfunction, decreased neurogenesis, increased neuronal cell death, hippocampal atrophy, and impairments in long-term potentiation (Lupien, McEwen, Gunnar, \& Heim, 2009). Psychosocial stress probably produces similar detrimental effects in humans. Childhood abuse in humans, for example, has been linked to specific alterations in the expression of genes for glucocorticoid receptors involved in the regulation of stressrelated neuroendocrine response (McGowan et al., 2009) as well as to alterations in prefrontal structures critical to emotion regulation (Hanson et al., 2010). Whether caused by physical or psychosocial stress, cumulative allostatic load may lead to developing psychopathologies in infancy, adolescence, and adulthood, such as cognitive deficits, sleep disturbance, schizophrenia, anxiety-related disorders, and depression (Shirtcliff, Dahl, \& Pollack, 2009).

Research also indicates that positive behaviors, specifically maternal nurturing (such as licking and grooming), induce beneficial alterations in the brain and in behavior that promote resilience (Champagne et al., 2008). Psychosocial factors, such as decreased levels of denial and avoidant coping behavior, increased levels of social engagement, positive emotion, and dispositional optimism, have all been shown to promote resilience (Feder, Nestler, \& Charney, 2009). Collectively, these data establish that our brains are continuously shaped both functionally and structurally by experience, and explicit training can capitalize on this to promote more adaptive brain functioning and prosocial behavior.

At the same time, substantial individual differences in emotion regulation beginning early in life play an important role in both resilience and vulnerability to psychopathology (Goldsmith, Pollak, \& Davidson, 2008). For example, when confronted by a stressful event, some individuals react with a context-appropriate emotional response and then rapidly return to baseline, whereas others show a more enduring maladaptive response and recover slowly. Such differences in reactivity and recovery can affect available cognitive resources. In school, for example, if a teen has an argument with a friend during a class break and is unable to recover quickly, the lingering consequences of emotional arousal into the next class could reduce learning. Such effects have been experimentally demonstrated; arousal and related anxiety interfere with attention and working memory, disrupting corresponding brain circuitry (Shackman, Maxwell, McMenamin, Greischar, \& Davidson, 2011; Shackman et al., 2006).

Considerable evidence has revealed developmental changes in the circuitry critical to emotion regulation, especially in PFC 
networks. When adolescents engage in tasks that require emotion regulation, they experience greater cognitive demand and greater activation in PFC regions than adults do (Blakemore \& Choudhury, 2006). Moreover, the circuitry of emotion regulation overlaps considerably with the circuitry of cognitive control. Yet despite enormous cognitive gains across childhood and adolescence (Paus, 2005), adolescents engage in more risk taking than adults (Steinberg, 2007). Rates of accidents, suicide, homicide, depression, substance abuse, violence, and risky sexual behaviors skyrocket during adolescence (Steinberg, 2009). These major sources of adolescent death and disability are related to difficulties in controlling emotion and behavior. Adolescents demonstrate decision making on par with adults under conditions of low arousal, but these cognitive processes are particularly impaired under intense emotional arousal (Steinberg, 2005). Consequently, it is particularly important to identify and incorporate into educational curricula strategies that promote skills in emotion regulation and self-awareness.

\section{Attention and Executive Function}

Executive functions (EFs) constitute a family of mental operations that involve attentional and cognitive control, planning, and working memory. Both socioemotional competence and academic achievement depend on EF skills (Blair \& Razza, 2007). However, although EF skills are central to competent behavior and thought, they degrade easily and are depletable. Psychosocial stressors, particularly during childhood, reduce their efficiency (Evans \& Schamberg, 2009). Individuals with low EF efficiency have greater difficulty inhibiting emotional expression, modulating emotions, and controlling both mind-wandering and rumination after an emotionally charged event (Kane et al., 2007). Self-control, a particular subcomponent of EF, has been found to be especially related to long-term outcomes. Moffitt et al. (2011) reported that self-control during childhood predicts physical health, substance dependence, personal finances, and criminal offenses in young adulthood in a cohort of 1,000 children followed from birth to age 32. Thus, well-functioning EF appears to benefit both cognitive control and emotion regulation. Also, it appears that PFC-related EF can be improved through behavioral training in young children (Blair \& Diamond, 2008; Diamond \& Lee, 2011) and both younger and older adults (Dahlin, Nyberg, Bäckman, \& Neely, 2008). In order to capitalize on the benefits of early EF skill training, new strategies that promote attentional control and EF will be particularly important to identify and to incorporate into the $\mathrm{K}-12$ educational curricula today.

\section{Self-Representation and Motivation}

Self-representations play key roles in EF, emotion and motivation, and social cognition (Dweck, 2008; Hassin, Bargh, \& Zimmerman, 2009). These representations index (a) the moment-to-moment physiological state of the body and visualspatial orientation, which spring from the spinothalamocortical networks (Craig, 2009), and (b) the narrative self based on memory, the default network, and cortical midline structures (LeGrand \& Ruby, 2009).

The narrative self emerges between ages 2 and 3 (Lewis \& Carmody, 2008). It affords a schema for assimilating and accommodating speech-mediated strategies and self-representations that motivate and regulate normative behavior from within (Dweck, 2008; Zelazo, 2004). During adolescence, the representational complexity and coherence of the narrative self increase, as do metacognitive strategies that enable introspection and reflection on past and imagined future selves (Harter, 2006).

Substantial individual differences in self-representations and related patterns of motivation arise from early childhood onward. These differences are associated with variation in readiness to learn and school achievement (Wigfield, Eccles, Schiefele, Roeser, \& Kean, 2006). Student beliefs that their intelligence is a fixed capacity, for example, are associated with maladaptive attributions following failure, greater test anxiety, and worse standardized test performance regardless of actual cognitive ability. Interventions that construe intelligence, and traits more broadly, to be malleable reduce anxiety and increase persistence and achievement (Dweck, 2008). Contemplative traditions feature this worldview in a salient way, viewing many traits, particularly those associated with virtuous character, as the product of skills that one can cultivate through training.

In addition, pessimism and a tendency to explain negative life events as one's own fault are core features of anxiety, depression, and academic problems beginning in childhood (Rood, Roelofs, Bogels, Nolen-Hoeksema, \& Schouten, 2009). However, studies are beginning to link mindfulness-based clinical interventions to reductions in anxiety and depression in adolescents (Biegel, Brown, Shapiro, \& Schubert, 2009). Although the mechanisms are not yet well understood, recent research suggests that through contemplative training, cognitive and affective processes can be engaged and disengaged more easily by means of dissociated networks of self-reference and self-regulation. Specifically, mindfulness practice seems to cultivate more present-oriented experiential forms of self-awareness (ESA) instead of introspective, narrative forms of self-awareness (NSA; Farb et al., 2007). The ESA involves relative increases in activity in a network comprising the ventral and dorsolateral PFC, right anterior insula, somatosensory cortex, and inferior parietal lobe, whereas the NSA involves relative increases in activation of cortical midline structures. These findings suggest that contemplative practices may reduce rumination and self-focused negative attributions by increasing present-oriented self-awareness (Watkins, 2008). In turn, such present-oriented forms of awareness may be beneficial for academic motivation and learning (Roeser \& Peck, 2009).

\section{Empathic Concern and Prosocial Behavior \\ Although empathy has a biological basis and dispositional differences in empathic responding and prosocial action exist}


from early life onward (Rothbart \& Bates, 2006), patterns of empathic responding and related prosocial action are relatively plastic both during childhood and adolescence and during adulthood. Specifically, studies of adults have revealed enhancements in functional activity of the insula, a key component of empathyrelated brain circuitry (Lutz, Brefczynski-Lewis, Johnstone, \& Davidson, 2008). This suggests that practice of forms of mental training designed to increase positive affect can enhance some of the neural circuitry underlying empathy, even in adulthood. Leiberg, Klimecki, and Singer (2011) demonstrated that shortterm compassion training based on traditional contemplative practices increases prosocial behavior on an economic decisionmaking game in a rigorous randomized controlled designed that involved comparison with an active comparison training group.

Emotion regulation also coordinates empathic concern and helping. To the extent that empathic concern for another in distress accompanies effectively regulated emotional arousal (such as fear), helping behavior becomes more likely; to the extent that empathic concern generates unregulated emotional distress, individuals are less likely to manifest helping behavior or to help others as a means of ending their own distress (Eisenberg, Smith, Sadovsky, \& Spinrad, 2004). Thus, insofar as emotion regulation skills can be trained, improvements in empathic responding to others in need could also follow. Given these considerations, new strategies that promote empathy and prosocial behavior in school settings are needed today (Steinberg \& Steinberg, 2006).

\section{PROSPECTS FOR AMERICAN EDUCATION}

The research we reviewed here provides a substantial empirical warrant to investigate the potential of contemplative practices for enhancing the quality of American public education. Many people believe that the kind of education needed in the 21st century includes developmental outcomes well beyond academic learning (Steinberg \& Steinberg, 2006), including young people's social, emotional, and ethical development (Noddings, 2005).

For instance, social-emotional learning (SEL) is an umbrella term for a variety of skills-based programs designed to help young people improve relationships with peers and adults, and to develop emotional understanding, self-control, and healthy values. O'Connell, Boat, and Warner (2009) explain that SEL programs have been shown to promote positive youth development while preventing mental health problems as well as substance abuse, violence, and other antisocial behavior. Furthermore, a recent meta-analysis of more than 250 experimental studies of universal SEL programs showed that they generally produced significant and meaningful improvements on achievement test performance; the effect was equivalent to an approximately $10 \%$ point gain on achievement testing (Durlak, Weissberg, Dymnicki, Taylor, \& Schellinger, 2011). Further, SEL programs have led to greater school attendance, less disciplinary action, and better grades among students. Recent interdisciplinary work in developmental neuroscience has likewise linked SEL programs to improvements in EF, including inhibitory control and working memory (Greenberg \& Rhoades, 2008).

Using contemplative practices in educational settings could both complement and add value beyond these kinds of programs and policies in two ways. First, a key characteristic of contemplative practices is that they represent forms of mental training that can induce plastic changes in the brain (Lutz, BrefczynskiLewis et al., 2008). At the heart of such practices is repetition and practice to cultivate more positive habits of mind. The idea of regularity of practice and repetition meshes well with neuroscientific understanding of how new connections are formed in the brain and the impact of regular practice on brain circuits and complex cognitive function (see Klingberg, 2010). Contemplative traditions provide a wealth of such practices that are already being adapted to the secular setting of schools and youth clinics (Black, Milam, \& Sussman, 2009; Burke, 2009; Roeser \& Peck, 2009) as well as in teachers and school leaders. Thus, a second benefit we see in introducing these practices into education is their enhancement of professional development in educators to nurture the very qualities we want educators, in turn, to nurture in students. Furthermore, the development of these skills in teachers may support their abilities to create cooperative and caring classroom climates and to support students through emotional conflicts (Jennings \& Greenberg, 2009). For example, one study found that mindfulness training reduced self-reported emotional, behavioral, and gastronomic stress symptoms among a sample of 21 secondary school student teachers (Winzelberg \& Luskin, 1999). Yet much more research is needed to identify the key ingredients that promote both teacher and student well-being while facilitating student cognitive and social-emotional learning.

Of course, our discussion may raise legitimate practical concerns about using contemplative practices in public school settings and whether there are worldview and church-state concerns implicated here. We believe these are important issues. Any use of contemplative practices in schools must necessarily be thoroughly secular, developmentally and culturally appropriate, and predicated on evidence-based practices. Key issues must be addressed, including, first and foremost, how do we ensure that we do no harm in this area of education? What are the realistic barriers and risks to implementing such practices in educational settings? How can we study the intraindividual biological and mental effects of contemplative practices on individuals, as well as their interpersonal effects in the contexts of families, schools, and communities? How do the quality of relationships and degree of interpersonal trust influence cultivation of these skills and positive qualities? What can we learn about the social and emotional dimensions of teaching and learning by introducing contemplative practices to young people in school? Is compassion best regarded as a skill that can be taught? Attention also should focus on whether skills learned in 
a contemplative-practice context transfer to the contexts of teaching and learning in the classroom, and on understanding what factors inhibit or facilitate such transfer.

Several scientific challenges must be addressed in creating and validating secular versions of contemplative practices for educational settings. First, continuing curriculum development must establish a set of sequenced pedagogical techniques for children and adolescents that are age appropriate, culturally sensitive, and amendable to careful scientific scrutiny. Although a number of models for secular contemplative education have recently been developed, they require further assessment and scrutiny (Birdee et al., 2009; Black et al., 2009; Burke, 2009). Second, significant issues of sustainability affect this kind of work. Research into how best to deliver contemplative programs to young people, if deemed advisable, would necessarily include a focus on preservice and inservice teacher education programs. Future research should focus as well on how contemplative practices might be used in these programs to nurture the types of positive qualities we discussed above and to examine how such practices might affect quality of instruction, stress and immunological reactivity, burnout within the profession, and health. In addition, the impact of cultivating positive teacher qualities on the quality of their relationships with students requires systematic study.

At present, these proposals concerning contemplative practices in education are speculative, and there is little evidence of their effectiveness. We call on researchers from a variety of disciplines to join in the study of their efficacy. As in all areas of evidence-based practice, the use of carefully designed randomized clinical trials will be a key part in legitimizing such efforts (see MacCoon et al., 2012, for a recent discussion of the complexity of this task as applied to contemplative interventions), as will careful qualitative analyses documenting processes of change in a deep and rich way. Along the way, research must address a number of related concerns. First, it is important to clearly specify the nature of the intervention and how the practices are adapted to be age appropriate. This should include clear descriptions of specific instructions and availability of manuals that provide such detail. Second, because many practices come from ones originally used with adults, investigation regarding the role of developmental processes is paramount. When joining neuroscience with education, cognitive science, developmental science, and prevention science, it will be important to explore whether there are particular "windows of opportunity" for the developing brain, mind, and social environments that may be beneficial times to introduce contemplative practices to young people in secular school settings. Third, there is a need to clearly specify the training necessary for fidelity of implementation, as well as the dosage and frequency necessary for beneficial effects. Fourth, in order to avoid unjustified broad claims, educational researchers should clearly specify the logic of their intervention models and more fully differentiate objectives and practices designed to achieve them. Fifth, trial designs should be lengthy enough to study the effects of such practices not only in the short term (posttest) but also in subsequent years. Sixth, to fully understand the potential impact of such practices, outcomes should be measured using multiple methods including those from neuroscience (both function and structure), behavioral measures of cognition and attention, physical health outcomes, academic performance on standardized tests, and reports by students, teachers, and parents of behavior and experience. Finally, economic analyses that clearly indicate the potential cost effectiveness and financial benefits of practices will be required and can greatly influence broad acceptance.

\section{CONCLUDING COMMENT}

Ideas drawn from contemplative practices that promise to improve the regulation of attention, emotion, motivation, social cognition, and behavior are one potential strategy for reducing the risks children face and improving both social and academic outcomes through schools today. A growing body of evidence in adults highlights the benefits of these practices in the regulation of attention and emotion, in cultivating empathy, and in altering brain function and structure to support these behavioral changes. However, there is a paucity of methodologically rigorous research confirming that such programs can improve children's developmental trajectories. In concluding their recent report on relations between childhood self-control and adult outcomes, Moffitt et al. (2011) suggest that "interventions addressing self-control might reduce a panoply of societal costs, save taxpayers money and promote prosperity." By conducting methodologically rigorous evaluations, the emerging field concerned with research on contemplative practices, education, developmental science, cognitive science, and neuroscience may come to a clearer understanding of whether, when, how, and for whom such practices can have substantial impact. Varma, McCandliss, and Schwartz (2008) noted the opportunities and challenges represented by the kind of transdisciplinary research effort that we describe here. Given the demonstrated influence of mental training on various forms of learning, studying the mind and brain in combination following specific educational "treatments" could be a novel way of assessing the efficacy of new educational practices. These ideas are congruent with recent calls for the field of education to engage in more rigorous scientific study and reforms based on emerging scientific insights (Alberts, 2009).

\section{REFERENCES}

Alberts, B. (2009). Editorial: Making a science of education. Science, $323,15$.

Andersen, S. L., \& Teicher, M. H. (2008). Stress, sensitive periods and maturational events in adolescent depression. Trends in Neurosciences, 31, 183-191.

Arias, A. J., Steinberg, K., Banga, A., \& Trestman, R. L. (2006). Systematic review of the efficacy of meditation techniques as treatments 
for medical illness. Journal of Alternative and Complementary Medicine, 12, 817-832.

Biegel, G. M., Brown, K. W., Shapiro, S. L., \& Schubert, C. M. (2009). Mindfulness-based stress reduction for the treatment of adolescent psychiatric outpatients: A randomized clinical trial. Journal of Counseling and Clinical Psychology, 77, 855-866.

Birdee, S. S., Yeh, G. Y., Wayne, P. M., Phillips, R. S., Davis, R. B., \& Gardiner, P. (2009). Clinical applications of yoga for the pediatric population: A systematic review. Academic Pediatrics, 9, 212-220.

Black, D. S., Milam, J., \& Sussman, S. (2009). Sitting-meditation interventions among youth: A review of treatment efficacy. Pediatrics, $124,532-541$.

Blair, C., \& Diamond, A. (2008). Biological processes in prevention and intervention: The promotion of self-regulation as a means of preventing school failure. Development and Psychopathology, 20, 899-911.

Blair, C., \& Razza, R. P. (2007). Relating effortful control, executive function, and false belief understanding to emerging math and literacy ability in kindergarten. Child Development, 78, 647-663.

Blakemore, S., \& Choudhury, S. (2006). Development of the adolescent brain: Implications of executive function and social cognition. Journal of Child Psychology and Psychiatry, 47, 296-312.

Burke, C. A. (2009). Mindfulness-based approaches with children and adolescents: A preliminary review of current research in an emergent field. Journal of Child and Family Studies, 19, 133-144.

Champagne, D. L., Bagot, R. C., van Hasselt, F., Famakers, G., Meaney, M. J., de Kloet, E. R., et al. (2008). Maternal care and hippocampal plasticity: Evidence for experience-dependent structural plasticity, altered synaptic functioning, and differential responsiveness to glucocorticoids and stress. Journal of Neuroscience, 28, 6037-6045.

Craig, A. D. (2009). How do you feel-now? The anterior insula and human awareness. Nature Reviews Neuroscience, 10, 59-70.

Dahlin, E., Nyberg, L., Bäckman, L., \& Neely, A. S. (2008). Plasticity of executive functioning in young and older adults: Immediate training gains, transfer, and long-term maintenance. Psychology and Aging, 23, 720-730.

Diamond, A., \& Lee, K. (2011). Interventions shown to aid executive function development in children 4 to 12 years old. Science, 333(6045), 959-964.

Durlak, J. A., Weissberg, R. P., Dymnicki, A. B., Taylor, R. D., \& Schellinger, K. B. (2011). The impact of enhancing students' social and emotional learning: A meta-analysis of school-based universal interventions. Child Development, 82, 405-432.

Dweck, C. (2008). Can personality be changed? The role of beliefs in personality and change. Current Directions in Psychological Science, 17, 391-394.

Eisenberg, N., Smith, C. L., Sadovsky, A., \& Spinrad, T. L. (2004). Effortful control: Relations with emotion regulation, adjustment, and socialization in childhood. In R. F. Baumeister \& K. D. Vohs (Eds.), Handbook of self-regulation: Research, theory, and applications (pp. 259-282). New York: Guilford.

Evans, G. W., \& Schamberg, M. A. (2009). Childhood poverty, chronic stress, and adult working memory. Proceedings of the National Academy of Sciences, 106, 6545-6549.

Farb, N. A., Segal, Z. V., Mayberg, H., Bean, J., McKeon, D., Fatima, Z., et al. (2007). Attending to the present: Mindfulness meditation reveals distinct neural modes of self-reference. Social Cognitive and Affective Neuroscience, 2, 313-322.

Feder, A., Nestler, E. J., \& Charney, D. S. (2009). Psychobiology and molecular genetics of resilience. Nature Reviews Neuroscience, 10, 446-457.
Fischer, K. W., \& Bidell, T. R. (1998). Dynamic development of psychological structures in action and thought. In W. Damon (Series Ed.) \& R. M. Lerner (Vol. Ed.), Handbook of child psychology: Vol. 1. Theoretical models of human development (5th ed., pp. 467-561). New York: Wiley.

Goldsmith, H. H., Pollak, S., \& Davidson, R. J. (2008). Developmental neuroscience perspectives on emotion regulation. Child Development Perspectives, 2, 132-140.

Greenberg, M. T., \& Rhoades, B. L. (2008). State-of-science review: Self regulation and executive function-What can teachers and schools do? London: Office of Science and Innovation Foresight Project: Mental Capital and Mental Wellbeing.

Hanson, J. L., Chung, M. K., Avants, B. B., Shritcliff, E. A., Gee, J. C., Davidson, R. J., \& Pollak, S. D. (2010). Early stress is associated with alterations in the orbitofrontal cortex: A tensor-based morphometry investigation of brain structure and behavioral risk. Journal of Neuroscience, 30, 7466-7472.

Harter, S. (2006). The self. In W. Damon \& R. M. Lener (Series Eds.) \& N. Eisenberg (Vol. Ed.), Handbook of child psychology: Vol. 3. Social, emotional, and personality development (6th ed., pp. 505570). New York: Wiley.

Hassin, R. R., Bargh, J. A., \& Zimmerman, S. (2009). Automatic and flexible: The case of non-conscious goal pursuit. Social Cognition, $27,20-36$.

Heckman, J. J. (2007). The economics, technology and neuroscience of human capability formation. Proceedings of the National Academy of Sciences, 104, 13250-13255.

Higgins, E. T. (1996). Knowledge activation: Accessibility, applicability, and salience. In E. T. Higgins \& A. W. Kruglanski (Eds.), Social psychology: Handbook of basic principles (pp. 133-168). New York: Guilford.

Jennings, P. A., \& Greenberg, M. (2009). The prosocial classroom: Teacher social and emotional competence in relation to child and classroom outcomes. Review of Educational Research, 79, 491-525.

Jha, A. P., Krompinger, J., \& Baime, M. J. (2007). Mindfulness training modifies subsystems of attention. Cognitive, Affective, \& Behavioral Neuroscience, 7, 109-119.

Kabat-Zinn, J., Lipworth, L., \& Burney, R. (1985). The clinical use of mindfulness meditation for the self-regulation of chronic pain. Journal of Behavioral Medicine, 8, 163-190.

Kane, M. J., Brown, L. H., McVay, J. C., Silvia, P. J., Myin-Germeys, I., \& Kwapil, T. R. (2007). For whom the mind wanders, and when: An experience-sampling study of working memory and executive control in daily life. Psychological Science, 18, 614-621.

Klingberg, T. (2010). Training and plasticity of working memory. Trends in Cognitive Science, 14, 317-324.

LeGrand, D., \& Ruby, P. (2009). What is self-specific? Theoretical investigation and critical review of neuroimaging results. Psychological Review, 116, 252-282.

Leiberg, S., Klimecki, O., \& Singer, T. (2011). Short-term compassion training increases prosocial behavior in a newly developed prosocial game. PLoS ONE, 6(3), el7798.

Lewis, M., \& Carmody, D. P. (2008). Self-representation and brain development. Developmental Psychology, 44, 1329-1334.

Lupien, S. J., McEwen, B. S., Gunnar, M. R., \& Heim, C. (2009). Effects of stress throughout the lifespan on the brain, behaviour and cognition. Nature Reviews Neuroscience, 10, 434-445.

Lutz, A., Brefczynski-Lewis, J. A., Johnstone, T., \& Davidson, R. J. (2008). Regulation of the neural circuitry of emotion by compassion meditation: Effects of meditative expertise. PLoS ONE, 3(3), el897. 
Lutz, A., Slagter, H. A., Dunne, J., \& Davidson, R. J. (2008). Attention regulation and monitoring in meditation. Trends in Cognitive Sciences, 12(4), 163-169.

Lutz, A., Slagter, H., Rawling, N., Francis, A., Greischar, L. L., \& Davidson, R. J. (2009). Mental training enhances attentional stability: Neural and behavioral evidence. Journal of Neuroscience, 29, 13418-13427.

MacCoon, D. G., Imel, Z. E., Rosenkranz, M. A., Sheftel, J. G., Weng, H. Y., Sullivan, J. C., et al. (2012). The validation of an active control intervention for Mindfulness Based Stress Reduction (MBSR). Behaviour Research and Therapy, 50, 3-12.

McGowan, P. O., Sasaki, A., D’Alessio, A. C., Dymov, S., Labonté, B., et al. (2009). Epigenetic regulation of the glucocorticoid receptor in human brain associates with childhood abuse. Nature Reviews Neuroscience., 12, 342-348.

Moffitt, T. E., Arseneault, L., Belsky, D., Dickson, N., Hancox, R. J., Harrington, H., et al. (2011). A gradient of childhood self-control predicts health, wealth, and public safety. Proceedings of the National Academy of Sciences, 108, 2693-2698.

Noddings, N., Ed. (2005). Educating citizens for global awareness. New York: Teachers' College Press.

O'Connell, M. E., Boat, T., \& Warner, K. E., Eds. (2009). Preventing mental, emotional, and behavioral disorders among young people: Progress and possibilities. Washington, DC: National Academies Press.

Ortner, C. N. M., Kilner, S. J., \& Zelazo, P. D. (2007). Mindfulness meditation and reduced emotional interference on a cognitive task. Motivation and Emotion, 31, 271-283.

Partnership for 21 st Century Skills. (2011). Homepage. Retrieved January 11, 2012, from http://www.p21.org

Paus, T. (2005). Mapping brain maturation and cognitive development during adolescence. Trends in Cognitive Sciences, 9, 60-68.

Paus, T., Keshavan, M., \& Giedd, J. N. (2008). Why do many psychiatric disorders emerge during adolescence? Nature Reviews Neuroscience, 9, 947-957.

Roeser, R. W., \& Peck, S. C. (2009). An education in awareness: Self, motivation, and self-regulated learning in contemplative perspective. Educational Psychologist, 44, 119-136.

Rood, L., Roelofs, J., Bogels, S. M., Nolen-Hoeksema, S., \& Schouten, E. (2009). The influence of emotion-focused rumination and distraction on depressive symptoms in non-clinical youth: A metaanalytic review. Clinical Psychology Review, 29, 607-616.

Rothbart, M. K., \& Bates, J. E. (2006). Temperament. In W. Damon \& R. Lerner (Series Eds.) \& N. Eisenberg (Ed.), Handbook of child psychology: Vol. 3. Social, emotional, and personality development (pp. 99-166). New York: Wiley.

Shackman, A. J., Maxwell, J. S., McMenamin, B. W., Greischar, L. L., \& Davidson, R. J. (2011). Stress potentiates early and attenuates late stages of visual processing. Journal of Neuroscience, 31, 11561161.
Shackman, A. J., Sarinopoulos, I., Maxwell, J. S., Pizzagalli, D. A., Lavric, A., \& Davidson, R. J. (2006). Anxiety selectively disrupts visuospatial working memory. Emotion, 6, 40-61.

Shirtcliff, E. A., Dahl, R. E., \& Pollack, S. D. (2009). Pubertal development: Correspondence between hormonal and physical development. Child Development, 80, 327-337.

Singer, T., \& Lamm, C. (2009). The social neuroscience of empathy. Annals of the New York Academy of Sciences, 1156, 81-96.

Slagter, H. A., Lutz, A., Greischar, L. L., Francis, A. D., Nieuwenhuis, S., Davis, J. M., \& Davidson, R. J. (2007). Mental training affects use of limited brain resources. PLoS Biology, 5, el38.

Steinberg, L. (2005). Cognitive and affective development in adolescence. Trends in Cognitive Sciences, 9, 69-74.

Steinberg, L. (2007). Risk taking in adolescence. New perspectives from brain and behavioral science. Current Directions in Psychological Science, 16, 55-59.

Steinberg, L. (2009). Adolescent development and juvenile justice. Annual Review of Clinical Psychology, 5, 459-485.

Steinberg, R. J., \& Steinberg, R. F., Eds. (2006). Optimizing student success in school with the other three R's: Reasoning, resilience, and responsibility. Greenwich, CT: New Age.

Urry, H. L., van Reekum, C. M., Johnstone, T., Kalin, N. H., Thurow, M. E., Schaefer, H. S., et al. (2006). Amygdala and ventromedial prefrontal cortex are inversely coupled during regulation of negative affect and predict the diurnal pattern of cortisol secretion among older adults. Journal of Neuroscience, 26, 4415-4425.

Varma, S., McCandliss, B. D., \& Schwartz, D. L. (2008). Scientific and pragmatic challenges for bridging education and neuroscience. Educational Researcher, 37, 140-152.

Watkins, E. R. (2008). Constructive and unconstructive repetitive thought. Psychological Bulletin, 134, 163-206.

Wigfield, A., Eccles, J. S., Schiefele, U., Roeser, R. W., \& Kean, P. D. (2006). Development of achievement motivation. In W. Damon \& R. M. Lerner (Series Eds.) \& N. Eisenberg (Vol. Ed.), Handbook of child psychology: Vol. 3. Social, emotional and personality development (6th ed., pp. 933-1002). New York: Wiley.

Winzelberg, A. L., \& Luskin, F. M. (1999). The effect of a meditation training in stress levels in secondary school teachers. Stress Medicine, 15, 69-77.

Witek-Janusek, L., Albuquerque, K., Chroniak, K. R., Chroniak, C., Durazo-Arvizu, R., \& Mathews, H. L. (2008). Effect of mindfulness based stress reduction on immune function, quality of life and coping in women newly diagnosed with early stage breast cancer. Brain, Behavior, and Immunity, 22, 969-981.

Zelazo, P. D. (2004). The development of conscious control in childhood. Trends in Cognitive Sciences, 8, 12-17.

Zins, J. E., Weissberg, R. P., Wang, M. C., \& Walberg, H. J. (2004). Building academic success on social and emotional learning. New York: Teachers' College Press. 